University of Wollongong

Research Online

Faculty of Engineering and Information

Faculty of Engineering and Information

Sciences - Papers: Part A

Sciences

$1-1-2012$

Thermal, microstructural and mechanical coupling analysis model for flatness change prediction during run-out table cooling in hot strip rolling

Xiao-dong Wang

University of Wollongong, xiaodong@uow.edu.au

Fei Li

Shougang Research Institute Of Technology

Zheng-yi Jiang

University of Wollongong, jiang@uow.edu.au

Follow this and additional works at: https://ro.uow.edu.au/eispapers

Part of the Engineering Commons, and the Science and Technology Studies Commons

Research Online is the open access institutional repository for the University of Wollongong. For further information contact the UOW Library: research-pubs@uow.edu.au 


\title{
Thermal, microstructural and mechanical coupling analysis model for flatness change prediction during run-out table cooling in hot strip rolling
}

\begin{abstract}
Non-uniformity of temperature distribution across strip width direction is the ultimate reason why the flatness defect occurs on the strip after cooling process although the strip is flat at the exit of finishing mill. One thermal, microstructural and mechanical coupling analysis model for predicting flatness change of steel strip during the run-out table cooling process was established using ABAQUS finite element software. K Esaka phase transformation kinetics model was employed to calculate the phase transformation, and coupled with temperature calculation using the user subroutine program HETVAL. Elasto-plasticity constitutive equations of steel material, in which conventional elastic and plastic strains, thermal strain, phase transformation strain and transformation induced plastic strain were considered, were derived and programmed in the user subroutine program UMAT. The conclusion that flatness of steel strip will develop to edge wave defect under the functions of the differential thermal and microstructural behaviors across strip width during the run-out table cooling procedure was acquired through the analysis results of this model. Calculation results of this analysis model agree well with the actual measurements and observation.
\end{abstract}

\section{Keywords}

prediction, during, run, model, out, analysis, table, coupling, cooling, hot, mechanical, strip, microstructural, flatness, thermal, rolling, change

\section{Disciplines}

Engineering | Science and Technology Studies

\section{Publication Details}

Wang, X., Li, F. \& Jiang, Z. (2012). Thermal, microstructural and mechanical coupling analysis model for flatness change prediction during run-out table cooling in hot strip rolling. Journal of Iron and Steel Research International, 19 (9), 43-51. 


\title{
Thermal, Microstructural and Mechanical Coupling Analysis Model for Flatness Change Prediction During Run-Out Table Cooling in Hot Strip Rolling
}

\author{
WANG Xiao-dong ${ }^{1,2}, \quad$ LI Fei ${ }^{1}, \quad$ JIANG Zheng-yi ${ }^{2}$ \\ (1. Shougang Research Institute of Technology, Shougang Group, Beijing 100043, China; 2. Faculty of \\ Engineering, University of Wollongong, Wollongong NSW 2522, Australia)
}

\begin{abstract}
Non-uniformity of temperature distribution across strip width direction is the ultimate reason why the flatness defect occurs on the strip after cooling process although the strip is flat at the exit of finishing mill. One thermal, microstructural and mechanical coupling analysis model for predicting flatness change of steel strip during the run-out table cooling process was established using ABAQUS finite element software. K Esaka phase transformation kinetics model was employed to calculate the phase transformation, and coupled with temperature calculation using the user subroutine program HETVAL. Elasto-plasticity constitutive equations of steel material, in which conventional elastic and plastic strains, thermal strain, phase transformation strain and transformation induced plastic strain were considered, were derived and programmed in the user subroutine program UMAT. The conclusion that flatness of steel strip will develop to edge wave defect under the functions of the differential thermal and microstructural behaviors across strip width during the run-out table cooling procedure was acquired through the analysis results of this model. Calculation results of this analysis model agree well with the actual measurements and observation.
\end{abstract}

Key words: hot rolled strip; internal stress; phase transformation; run-out table cooling; flatness

It is a very complicated process for strip's cooling on the run-out table during which thermal stress will be generated due to uneven temperature distribution and cooling along transverse direction. Other than the thermal stress, the difference in phase transformation due to uneven temperature distribution and cooling also leads to internal stress generation in the strip. Both of thermal and transformation stresses are the sources of residual stress causing strip flatness defects. Therefore, residual stress must be controlled as lower as possible in actual production. Many researches ${ }^{[1-2]}$ on heat transfer and metallurgical phenomena during cooling of hot rolled strip have been done. In the contrast, the researches on how strip flatness changes during cooling are few, and yet no consistent conclusion is reached.

With the increasing demand on strip flatness quality, to analyze the deformations of hot rolled product after cooling, precise investigation of thermal stress developed during the cooling is very important, and has received significant attention ${ }^{[3-11]}$.
There have been two contradictory viewpoints about how the strip flatness changes during the cooling after hot rolling. The one is that the edge wave will happen after cooling of steel strip even if the flatness before the coiling stage is good or center wave ${ }^{[3-5,7.10]}$. The other one is that the center wave will happen after cooling of steel strip ${ }^{[8-9\rfloor}$.

Many researches ${ }^{[12-15]}$ worldwide have given focus on thermal, mechanical and metallurgical coupling phenomena to analyze the residual stress and deformation during the heat treatment procedure of metal. The phase transformation induced plasticity (TRIP) has an important influence on the residual stress field in the material after quenching. TRIP, not a kind of normal plasticity behavior, can be observed when the metallurgical phase transformation happens although the external stress is much lower than yield stress limit of the material. The constitutive model in which whether or not TRIP effect is considered is important for investigating temperature, phase transformation and stress-strain interac- 
tions during steel heat treatment ${ }^{[12-15]}$. However, TRIP effect has not been emphasized in the early research works of deformation behavior analysis during the steel strip's run-out table cooling.

For thoroughly investigating how the strip flatness changes during and after cooling, an FE model in which temperature, phase transformation and stress/strain were fully coupled to analyze the internal stress evolution has been established using ABAQUS in this work, and the results of the FE model were compared with the measurements.

\section{Mathematic Models}

\subsection{Thermal model}

The thermo-mechanical analysis involves solving the transient heat transfer and thermal stress problem describing the temperature and thermal stress variations with time in the strip during cooling. During the run-out table cooling process, the temperature distribution in the strip can be calculated using the governing partial differential equation shown as follows:

$$
\begin{gathered}
\frac{\partial}{\partial x}\left[\lambda_{x}(T) \frac{\partial T}{\partial x}\right]+\frac{\partial}{\partial y}\left[\lambda_{y}(T) \frac{\partial T}{\partial y}\right]+\frac{\partial}{\partial z}\left[\lambda_{z}(T) \frac{\partial T}{\partial z}\right]+ \\
\dot{q}=\rho c_{p}(T) \frac{\partial T}{\partial t}
\end{gathered}
$$

where, $\rho$ is the density; $c_{p}(T)$ is the temperature dependent specific heat; $\lambda(T)$ is the temperature dependent thermal conductivity of the material with the subscripts $x, y$ and $z$ representing its components in three directions of width, length and thickness, respectively; $T$ and $t$ are temperature and time, respectively; and $\dot{q}$ is the rate of heat generation term representing the internal heat source released due to phase transformation of austenite.

\section{2 Phase transformation model}

Hot rolled plain low carbon steel strip was selected as the research object. The plain $\mathrm{C}-\mathrm{Mn}$ steel phase transformation dynamic model derived by $\mathrm{K}$ Esaka that was introduced by reviewing work of $\mathrm{O} \mathrm{Kwon}^{[16]}$, was employed in this work. K Esaka phase transformation dynamic model was established on the basis of Avrami function and was suitable to be applied in C-Mn steel. Two factors of austenite grain diameter $D_{\gamma}$ before phase transformation and retained strain $\Delta \varepsilon$ affecting $k$ value were considered in this model, and the main structure of this model is as follows:

$$
\begin{aligned}
X= & X_{\max }\left\{1-\exp \left[-\frac{1}{2.24}\left|\frac{2.24}{D_{\gamma}} q+0.114(\Delta \varepsilon)^{2}\right| \times\right.\right. \\
& {\left.\left.[1+B(\Delta \varepsilon)] k(t-\tau)^{n}\right]\right\} }
\end{aligned}
$$

where, $X$ and $X_{\max }$ are transformed fraction and the maximum fraction of one phase, respectively; incubation period $\tau$ and parameters $k$ and $n$ used in phase transformations of austenite to ferrite, pearlite and bainite; $q, X_{\max }$ related to maximum ferrite fraction $F_{\max }$, pearlite fraction $P_{\max }$ and bainite fraction $B_{\max }$ are all illustrated in Ref. [16].

\section{3 Constitutive equations}

Total strain in steel strip can be decomposed into five parts due to different causes during the cooling procedure, and it can be written to be the incremental form ${ }^{[12\rfloor}$ as follows

$$
\mathrm{d}\{\boldsymbol{\varepsilon}\}=\mathrm{d}\{\varepsilon\}^{\mathrm{e}}+\mathrm{d}\{\boldsymbol{\varepsilon}\}^{\text {th }}+\mathrm{d}\{\boldsymbol{\varepsilon}\}^{\mathrm{p}}+\mathrm{d}\{\boldsymbol{\varepsilon}\}^{\mathrm{tr}}+\mathrm{d}\{\boldsymbol{\varepsilon}\}^{\mathrm{tp}}
$$

where, symbols in \{\} always represent the vectors in this work; $\mathrm{d}\{\varepsilon\}^{\mathrm{e}}, \mathrm{d}\{\varepsilon\}^{\text {th }}$ and $\mathrm{d}\{\varepsilon\}^{\mathrm{p}}$ are the increments of elastic strain, thermal strain and conventional plastic strain, respectively; $\mathrm{d}\{\varepsilon\}^{\mathrm{tr}}$ and $\mathrm{d}\{\boldsymbol{\varepsilon}\}^{\mathrm{tP}}$, relevant to phase transformation, are increments of phase transformation strain due to phase volume change and phase transformation induced plastic strain, respectively.

Thermal strains due to non-uniform temperature distribution depend on microstructural compositions:

$$
\mathrm{d}\{\varepsilon\}^{\text {th }}=\left(X_{\mathrm{A}} \alpha_{\mathrm{A}}+X_{\mathrm{F}} \alpha_{\mathrm{F}}+X_{\mathrm{P}} \alpha_{\mathrm{P}}+X_{\mathrm{B}} \alpha_{\mathrm{B}}\right) \dot{T} \cdot \delta_{i j}
$$
where, $\alpha$ is thermal expansion coefficient, ${ }^{C} \mathrm{C}^{-1} ; \delta_{i j}=$ $\left\{\begin{array}{ll}1 & i=j \\ 0 & i \neq j\end{array}\right.$ is Kronecker tensor.

Phase transformation strain increment due to phase volume change during the phase transformation process is calculated as follows:

$$
\mathrm{d}\{\varepsilon\}^{\mathrm{tr}}=\left(\sum_{k=2}^{i} \beta_{k} \dot{X}_{k}\right) \cdot \delta_{i j}
$$

where, $\beta$ is phase transformation expansion coefficient; $I$ is the total phase number, and equals to 3 , whereby 1,2 , and 3 represent austenite, ferrite, and pearlite, respectively.

Greenwood-Johnson theory was used to describe TRIP effects because there are only transformations from austenite to ferrite and pearlite in the steel grade studied in this work. In this work, Leblond extended model ${ }^{[17]}$ was selected as the calculating formulation of transformation induced plastic strain composition of the material constitutive equation, and it can be expressed as follows:

$$
\mathrm{d}\{\varepsilon\}_{i j}^{\mathrm{tp}}= \begin{cases}0 & \text { if } X \leqslant 0.03 \\ -\frac{2 \Delta \varepsilon_{12}}{\sigma_{\mathrm{A}}^{\mathrm{y}}} \cdot \ln (X) \cdot \dot{X} \cdot \frac{3}{2} \cdot \\ h\left(\frac{\sigma^{\mathrm{eq}}}{\sigma^{y}}\right) \cdot S_{i j} & \text { if } X>0.03\end{cases}
$$

where, $\Delta \varepsilon_{12}$ is the volume change of austenite to new 
generated phase; $\sigma_{\mathrm{A}}^{\mathrm{y}}$ is the yield stress of austenite; $\sigma^{y}$ is the yield stress of mixed structure; $\sigma^{\text {eq }}$ is the equivalent stress; $h\left(\frac{\sigma^{\mathrm{eq}}}{\sigma^{\mathrm{y}}}\right)$ is the nonlinear term when the exerted stress is more than one half of $\sigma^{y} ; S_{i j}$ is the deviatoric stress tensor:

$$
h\left(\frac{\sigma^{\mathrm{eq}}}{\sigma^{\mathrm{y}}}\right)= \begin{cases}1 & \text { if } \frac{\sigma^{\mathrm{eq}}}{\sigma^{\mathrm{y}}} \leqslant \frac{1}{2} \\ 1+3.5\left(\frac{\sigma^{\mathrm{eq}}}{\sigma^{\mathrm{y}}}-\frac{1}{2}\right) & \text { if } \frac{\sigma^{\mathrm{eq}}}{\sigma^{y}}>\frac{1}{2}\end{cases}
$$

Derivation work on material constitutive equations can be divided into two kinds of segments, namely elastic and plastic deformations. At beginning of each step during the calculation, the program will judge whether phase transformation has started or not. If phase transformation occurs and its volume fraction is larger than 0.03 , according to Eqn. (6), transformation induced plastic flow happens even the equivalent stress is lower than the yield stress. Transformation plastic strain flows along the direction of the current derivatoric stress. When transformation induced plastic behavior happens, constitutive function can be expressed as follows ${ }^{[12]}$ :

$$
\mathrm{d}\{\sigma\}=[D]_{\mathrm{tp}} \cdot\left(\mathrm{d}\{\varepsilon\}-\mathrm{d}\{\widetilde{\varepsilon}\}^{\text {th }}-\mathrm{d}\{\varepsilon\}^{\mathrm{tr}}\right)
$$

where

$$
[D]_{\mathrm{tp}}=K \mathbf{1} \otimes \mathbf{1}+2 G \eta_{0}\left|\boldsymbol{I}-\frac{1}{3} \mathbf{1} \otimes \mathbf{1}\right|-2 G \gamma_{0} \boldsymbol{n} \otimes \boldsymbol{n}
$$

$K=\frac{E_{p}(T)}{3\left[1-2 v_{p}(T)\right]}$ and $G=\frac{E_{p}(T)}{2\left[1+v_{p}(T)\right]}$ are bulk and shear modules, respectively; $\boldsymbol{I}$ and $\boldsymbol{I}$ are the second order and the fourth order identity tensors, respectively; $\eta_{0}$ and $\gamma_{0}$ can be calculated according to the formulae in Ref. [12]. In the elastic deformation region, the total strain increment can be expressed as follows:

$$
\mathrm{d}\{\boldsymbol{\varepsilon}\}=\mathrm{d}\{\boldsymbol{\varepsilon}\}^{\mathrm{e}}+\mathrm{d}\{\boldsymbol{\varepsilon}\}^{\text {th }}+\mathrm{d}\{\boldsymbol{\varepsilon}\}^{\text {tr }}+\mathrm{d}\{\boldsymbol{\varepsilon}\}^{\text {tp }}
$$

The elastic strain is linearly related to the applied stress by isotropic Hooke' s law, and then stress increment $\sigma_{i j}$ can be derived and expressed as the vector form in which material properties parameters depended on temperature are considered.

$$
\mathrm{d}\{\sigma\}=[D]_{\mathrm{el}} \cdot\left(\mathrm{d}\{\boldsymbol{\varepsilon}\}-\mathrm{d}\{\widetilde{\varepsilon}\}^{\text {th }}-\mathrm{d}\{\varepsilon\}^{\mathrm{tr}}-\mathrm{d}\{\boldsymbol{\varepsilon}\}^{\mathrm{tp}}\right)(11)
$$

where

$$
\begin{aligned}
\mathrm{d}\{\widetilde{\varepsilon}\}^{\text {th }}= & {\left[\left(X_{\mathrm{A}} \alpha_{\mathrm{A}}+X_{\mathrm{F}} \alpha_{\mathrm{F}}+X_{\mathrm{P} \alpha_{\mathrm{P}}}+X_{\mathrm{B}} \alpha_{\mathrm{B}}\right) \cdot\right.} \\
& {\left.\left[\begin{array}{llllll}
1 & 1 & 1 & 0 & 0 & 0
\end{array}\right]^{\mathrm{T}}+\frac{\mathrm{d}[D]_{\mathrm{el}}^{-1}}{\mathrm{~d} T}\{\sigma\}\right] \dot{T} }
\end{aligned}
$$

$[D]_{\mathrm{el}}$ can be described as the tensor form:

$$
\boldsymbol{D}_{\mathrm{el}}=K \mathbf{1} \otimes \mathbf{1}+2 G[\boldsymbol{I}-(1 / 3) \mathbf{1} \otimes \mathbf{1}]
$$

When the material undergoes macro plastic deformation, based on the relationship between elastic stress and elastic strain, stress increment can be rewritten as follows:

$$
\begin{aligned}
\mathrm{d}\{\sigma\}= & {[D]_{\mathrm{el}} \cdot\left(\mathrm{d}\{\varepsilon\}-\mathrm{d}\{\varepsilon\}^{\mathrm{p}}-\mathrm{d}\{\tilde{\varepsilon}\}^{\text {th }}-\right.} \\
& \left.\mathrm{d}\{\boldsymbol{\varepsilon}\}^{\mathrm{tr}}-\mathrm{d}\{\varepsilon\}^{\mathrm{tp}}\right)
\end{aligned}
$$

According to isotropic hardening Von-Mises yield criterion and Prandtl-Reuss plastic flow rule, assume $H$ is the rate of slope at any one point of hardening curve $\bar{\sigma}-\int \mathrm{d} \bar{\varepsilon}^{p}$. Through derivation, when material undergoes plastic deformation, the constitutive equation Eqn. (15) was expressed as follows

$$
\mathrm{d}\{\sigma\}=[D]_{\mathrm{ep}} \cdot\left(\mathrm{d}\{\varepsilon\}-\mathrm{d}\{\bar{\varepsilon}\}^{\text {th }}-\mathrm{d}\{\varepsilon\}^{\mathrm{tr}}-\mathrm{d}\{\varepsilon\}^{\mathrm{tp}}\right)(15)
$$
where

$$
[D]_{\mathrm{ep}}=[D]_{\mathrm{el}}-\frac{[D]_{\mathrm{el}} \frac{\partial \bar{\sigma}}{\{\hat{\alpha}\}} \cdot\left(\frac{\partial \bar{\sigma}}{\partial\{\sigma\}}\right)^{\mathrm{T}}[D]_{\mathrm{el}}}{H+\left(\frac{\partial \bar{\sigma}}{\partial\{\sigma\}}\right)^{\mathrm{T}}[D]_{\mathrm{el}} \frac{\partial \bar{\sigma}}{\partial\{\sigma\}}}
$$

\section{FEM Analysis Model}

This numerical analysis work was carried out on the basis of the actual production processes and conditions in one Hot Strip Mill in Shougang Group. The run-out table is $130 \mathrm{~m}$ long and the behavior of a strip with a certain length was investigated. A fully coupled temperature-displacement analysis of the internal stress in the strip developed during cooling was carried out using ABAQUS Version 6. $5^{[18]}$, which provides the pre- and post-processors and the solvers for the finite element analysis. Additional user subroutines offer the user powerful tools to accurately simulate the non-linear boundary conditions, loads, and constitutive behavior of materials.

\section{1 Meshing of physical model}

The steel grade of the strip selected to be calculation object is HP295. The length, width and thickness of the strip segment to be computed are $6 \mathrm{~m}, 1200 \mathrm{~mm}$ and $4.0 \mathrm{~mm}$, respectively. Strip velocity was assumed to be $6.0 \mathrm{~m} / \mathrm{s}$. The strip is cooled from 880 to $620^{\circ} \mathrm{C}$ on the run-out table. Model was established in the rectangular coordinate system, and directions 1,2 and 3 represent $x, y$, and $z$ respectively. Element type is C3D8T, and element size is $30 \mathrm{~mm}$. Meshes of the computation model are shown in Fig. 1.

\section{2 Physical parameters}

The material physical parameters varying with temperature have important effects on the results of computation. It is necessary to correctly select the physical parameters for ensuring the computation precision of temperature and internal stress. Low carbon 


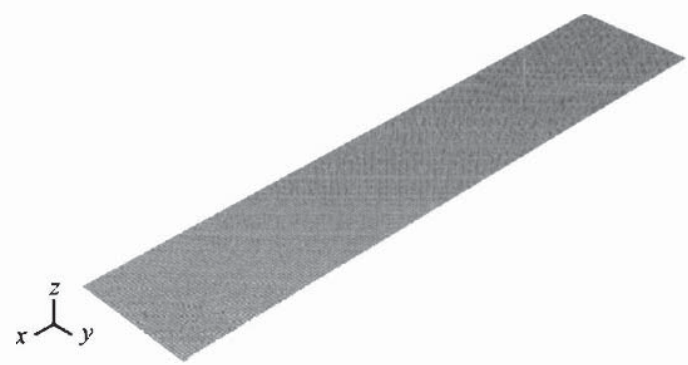

Fig. 1 Meshes of computation model

steel HP295 was selected as the computation subject, and material characteristic parameters such as specific heat, thermal conductivity coefficient were provided by hot strip mill of Qiangang Iron and Steel Company of Shougang Group as shown in Table 1. Young's modulus and Poisson's ratio, hardening curves, which were determined according to Ref. [8], were defined in the input file and passed into the user subroutine program UMAT. Other material characteristic parameters including density, yield stress of every phase are shown in Fig. 2, and thermal and phase expansion coefficients are determined according to Ref. [5]. They all depend on the temperature, and

Table 1 Thermal conductivity coefficient and specific heat depended on temperature

\begin{tabular}{ccc}
$\begin{array}{c}\text { Temperature/ } \\
\mathrm{C}\end{array}$ & $\begin{array}{r}\text { Thermal conductivity } \\
\text { coefficient/ } \\
\left(\mathrm{W} \cdot \mathrm{m}^{-1} \cdot \mathrm{K}^{-1}\right)\end{array}$ & $\begin{array}{c}\text { Specific heat/ } \\
\left(\mathrm{J} \cdot \mathrm{kg}^{-1} \cdot \mathrm{K}^{-1}\right)\end{array}$ \\
\hline 550 & 34.4 & 692 \\
600 & 31.8 & 735 \\
650 & 28.5 & 752 \\
700 & 27.2 & 866 \\
750 & 26.2 & 1021 \\
800 & 25.8 & 839 \\
850 & 25.5 & 742 \\
900 & 25.4 & 725 \\
950 & 25.5 & 718 \\
\hline
\end{tabular}

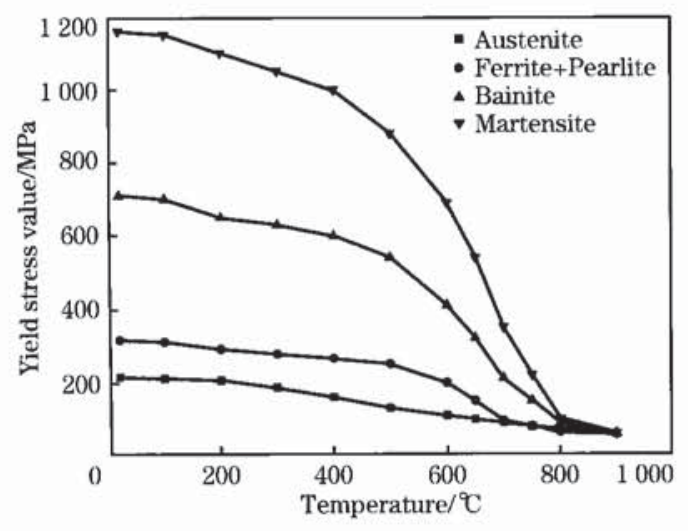

Fig. 2 Yield stress of every solid phase are directly defined in the user subroutine program UMAT. Linear mixed rule was employed to calculate the parameters on the given temperature points, and then the value located within two temperature points was obtained by linear interpolation method.

\section{3 Boundary conditions}

To solve the temperature differential equation, it is very important to define boundary conditions accurately. The laminar cooling of the hot rolled strip on the run-out table is a relatively complicated process of heat transfer. The boundary conditions can be generalized to be: 1) convection heat transfers between the strip and cooling water or between the strip and air; 2) the thermal radiation from the strip to the atmosphere. The boundary conditions can be described as follows

$$
\left\{\begin{array}{l}
-\lambda \frac{\partial T}{\partial n}=h_{\mathrm{w} 1}\left(T-T_{\mathrm{w} 1}\right) \\
-\lambda \frac{\partial T}{\partial n}=h_{\mathrm{w} 2}\left(T-T_{\mathrm{w} 2}\right)+\phi \xi\left(T^{4}-T_{\mathrm{w} 2}^{\mathrm{u}}\right)
\end{array}\right.
$$

where, $n$ is normal direction of strip's surface; $h_{\mathrm{w} 1}$ and $h_{\mathrm{w} 2}$ are convection heat transfer coefficients on the strip surface between the cooling water and the air, respectively; $\phi$ is Stefan-Boltzmann constant, $5.6697 \times 10^{-8} \mathrm{~W} \cdot \mathrm{m}^{-2} \cdot \mathrm{K}^{-1}$; $\xi$ is emissivity and setup to be 0.7 in this model; $T_{\mathrm{w} 1}$ and $T_{\mathrm{w} 2}$ are temperatures of cooling water and atmosphere, respectively.

Boundary constraint conditions were defined during the establishment of FEM model. Full displacement constraint is applied to one end of the strip segment, while the other end is assumed to be free. Two strip edges are assumed to be simply support condition along $y$ direction normal to the rolling direction.

\section{4 Initial conditions}

When steel strip leaves the last stand of finishing mill and before it enters into cooling zone, one initial temperature field and one initial stress distribution already exist. Both of the initial temperature field and initial stress are not uniform.

Actual temperature measurements along transverse direction on the strip were carried out by means of two infrared thermal imagers at the exit of last stand of finishing mill and the entry of the downcoiler, respectively. Transverse temperature distribution can be fitted to a fourth order polynomial function of transverse coordinate using the least squares method. By means of user subroutine program UTEMP, initial temperature field shown as Fig. 3 was defined in the model. 


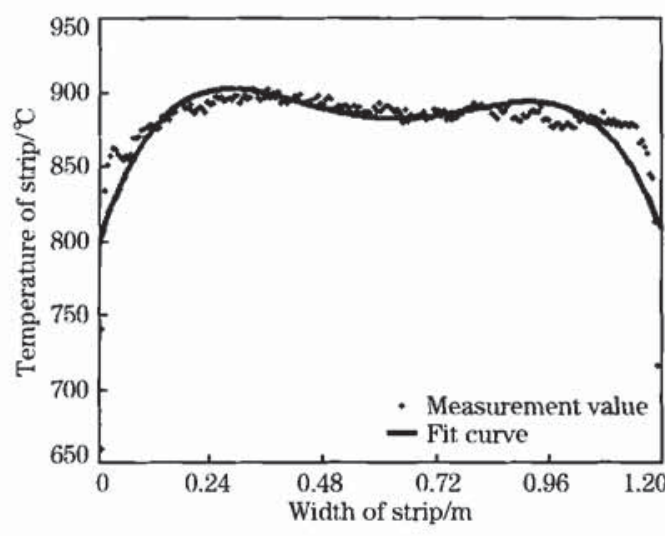

Fig. 3 Initial temperature distribution along transverse direction of strip

After finish rolling, stress distribution representing certain flatness pattern already exists in the strip. To simulate the initial flatness, initial stress distribution should be loaded. This initial stress distribution can be expressed using relative elongation difference along transverse direction of the strip. Same as the initial temperature, initial stress was loaded using user subroutine program SIGINI. The detailed was illustrated in Ref. [20].

As two initial parameters in phase transformation calculation, austenite grain size and retained strain also need to be defined. According to the research result obtained by ZHANG Mai-cang ${ }^{[21]}$, austenite grain diameter after hot rolling and before the cooling is located between 20 and $40 \mu \mathrm{m}$. The steel chemical contents and processing parameters in Ref. [21] are similar as those of this work. Therefore austenite grain diameter $D_{y}$ is assumed to be $20 \mu \mathrm{m}$.

Retained strain $\Delta \varepsilon$ in strip after finish rolling is calculated as follows:

$$
\Delta \varepsilon=\left(f_{\mathrm{D}} \cdot \varepsilon_{\mathrm{c}}+f_{\mathrm{N}} \cdot \varepsilon\right) \cdot \exp \left[1-\left(t / \tau_{t}\right)^{k}\right]
$$

where, $f_{\mathrm{D}}$ and $f_{\mathrm{N}}$ are volume fractions of dynamic recrystallization and non-recrystallization, respectively, determined by Esaka calculation models seen from Ref. [16]; $\varepsilon_{\mathrm{c}}$ is deformation value when recrystallization begins; $\tau_{t}=8.46 \times 10^{-9} \exp (43800 / R T)$; $R$ is gas constant; $\varepsilon$ is the total deformation from reduction as defined below

$$
\varepsilon=-\frac{2}{\sqrt{3}} \ln (1-P)
$$

where, $P=(H-h) / H$ is reduction of thickness; $H$ and $h$ are thickness values before and after the de formation process respectively.

\section{Results and Discussion}

In this work, HP295 steel that was hot rolled at one hot strip mill of Qiangang Iron and Steel Company of Shougang Group was selected to be the simulation object in the internal stress calculation model of laminar cooling process and the chemical composition is shown in Table 2 .

Table 2 Chemical composition of steel SPHC used in simulation (mass percent, \%)

\begin{tabular}{cccccc}
\hline $\mathrm{C}$ & $\mathrm{Si}$ & $\mathrm{Mn}$ & $\mathrm{P}$ & $\mathrm{S}$ & $\mathrm{Al}$ \\
\hline 0.174 & 0.014 & 0.9 & 0.011 & 0.009 & 0.02 \\
\hline
\end{tabular}

Computation procedure in the FEM model is divided into three steps.

1) The first step is air cooling process of $12.7 \mathrm{~m}$ in distance from the last stand finishing mill $\mathrm{F} 6$ to the first row of laminar water cooling pipes. Air temperature and its convective coefficient were assumed to be $30{ }^{\circ} \mathrm{C}$ and $30 \mathrm{~W} \cdot \mathrm{m}^{-2} \cdot \mathrm{K}^{-1}$, respectively.

2) The second step is water cooling process lasting for $10 \mathrm{~s}$, and heat flux values on strip top surface and bottom surface were set to be $-2.4 \times 10^{7}$ and $-1.8 \times$ $10^{7} \mathrm{~W} \cdot \mathrm{m}^{-2}$, respectively. The atmosphere temperature was $28{ }^{\circ} \mathrm{C}$.

3) The third step is also air cooling and the time is $4 \mathrm{~s}$. The related parameters for boundary conditions are the same as those of the first one.

\section{1 Realization of thermal, metallurgical and me- chanical coupling analysis}

$\mathrm{K}$ Esaka phase transformation model described before was employed to calculate the microstructural evolution, and it was described in the user subroutine program HETVAL. Both of transformation phase fractions and latent heat were calculated, therefore coupling between phase transformation and temperature field was realized. The mechanical constitutive behavior of the material in 2.3 was described in the user subroutine program UMAT. Many important parameters such as phase fractions, phase increments, incubation time of phase transformation, beginning transformation temperature, initial residual strain and austenite grain diameter, and so on were defined as the state variables and initialized in the user subroutine program SDVINI. They were updated in the calculation processes of HETVAL and UMAT. The flow charts of subroutines HETVAL and UMAT are shown as Fig. 4 and Fig. 5, respectively. Full coupled analysis of thermal, mechanical and microstructural behaviours was carried out by means of these subroutines. 


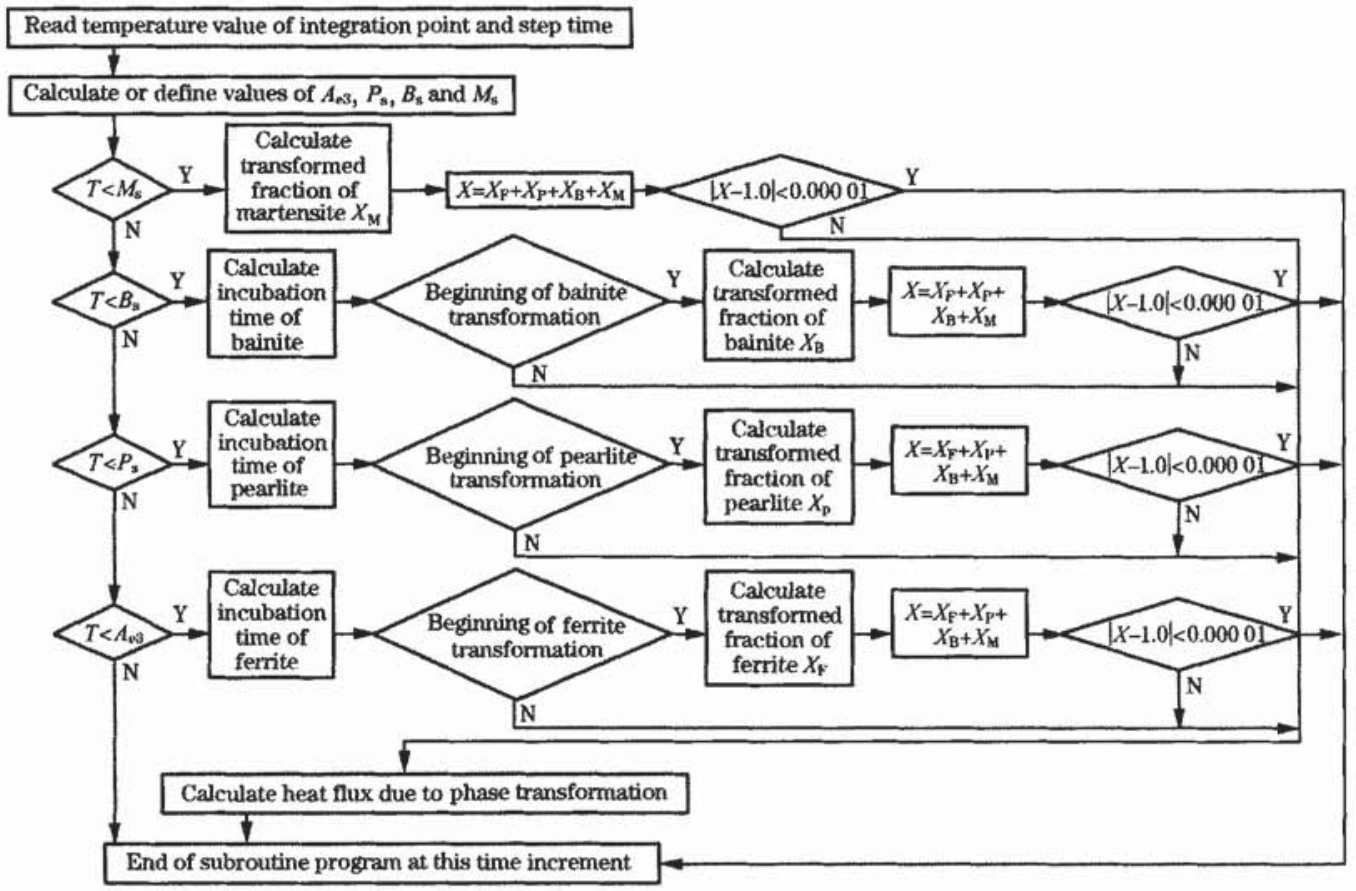

Fig. 4 Calculation flow chart of subroutine program HETVAL

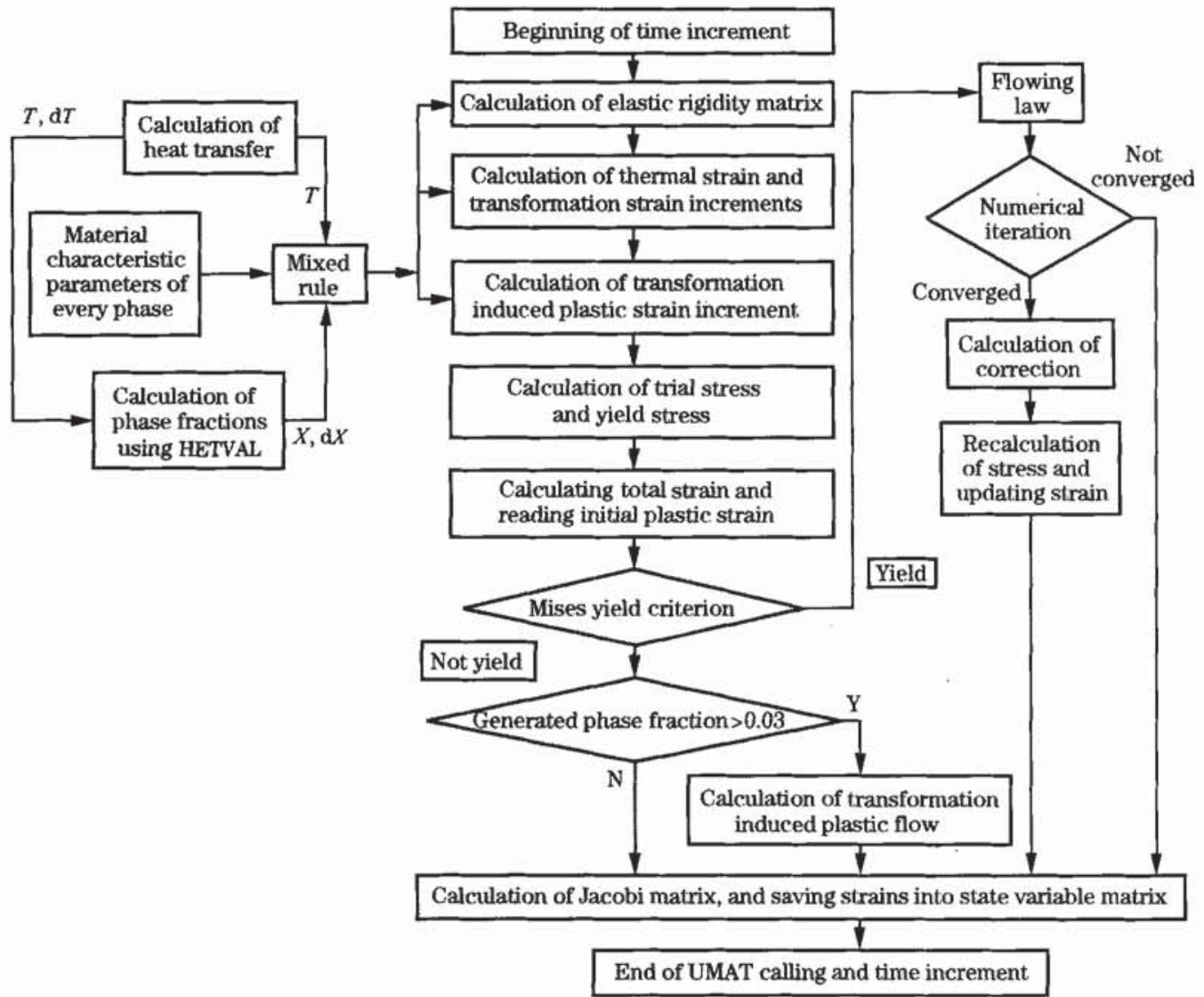

Fig. 5 Calculation flow chart of subroutine program UMAT

\section{2 Temperature and phase transformation calcula-} tion results

Precision of temperature computation is the founda- tion of the internal stress analysis. The calculation result of temperature evolution along strip's transverse direction during the run-out table cooling is 
shown in Fig. 6. The temperature on the strip center at the exit of finish rolling mill is $880^{\circ} \mathrm{C}$, while it is about $620^{\circ} \mathrm{C}$ after the cooling. Temperature evolution calculation result is of consistency with the temperature control requirement of actual production line. Temperature calculation of this analysis model has a high accuracy. Strip has a nonuniform temperature distribution along its transverse direction with a certain temperature drop existing within strip edge region, and this nonuniform distribution of temperature retains until the end of the run-out table cooling.

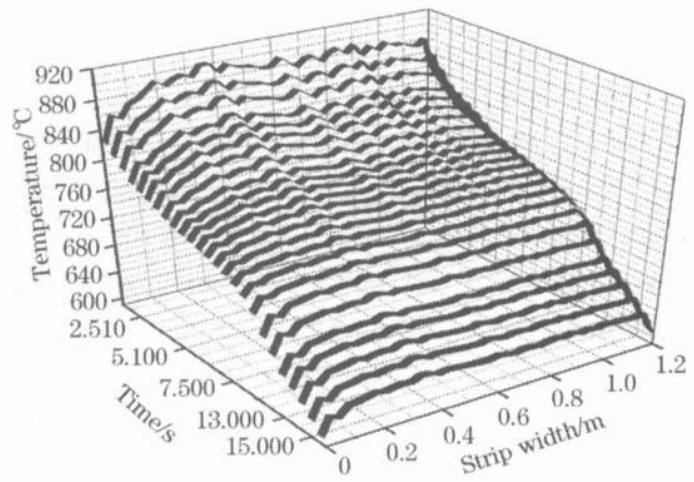

Fig. 6 Temperature evolution along strip's transverse direction

Fig. 7 is the calculation results of phase transformation dependent on temperature at the center and edge of the strip. The temperature trajectories on the center and edge can also be seen as shown in Fig. 7. The temperature difference between center and edge is large at the beginning of cooling process, and then becomes small at the end of cooling process. Phase transformation behaviors happen mainly during the water cooling process, and incubation time is very short. At the end of the cooling, austenite all transforms to ferrite and pearlite, and there is microstructure fraction difference between the center and edge.

Seven samples of hot rolled steel strip HP295 with

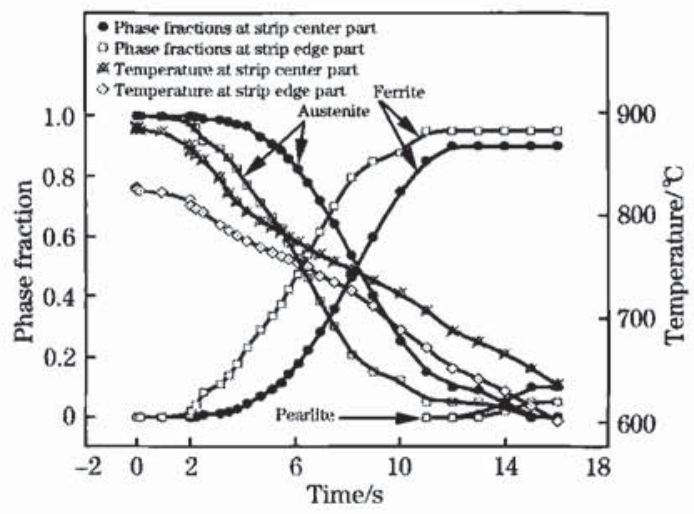

Fig. 7 Phase transformation and temperature trajectories at center and edge of strip
$1200 \mathrm{~mm}$ in width and $4.0 \mathrm{~mm}$ in thickness were cut. Microstructure measurements were made at nine positions evenly located along the transverse direction on every sample. The measurement and calculation results of microstructure are shown in Fig. 8. Ferrite fraction reaches as high as about $95 \%$ at center part of strip and as low as about $80 \%$ at edge part of strip, while on the contrary pearlite fraction is about $20 \%$ and $5 \%$ at center and edge parts of strip, respectively. Calculated results of phase fractions along transverse direction of strip agree well with the measurement.

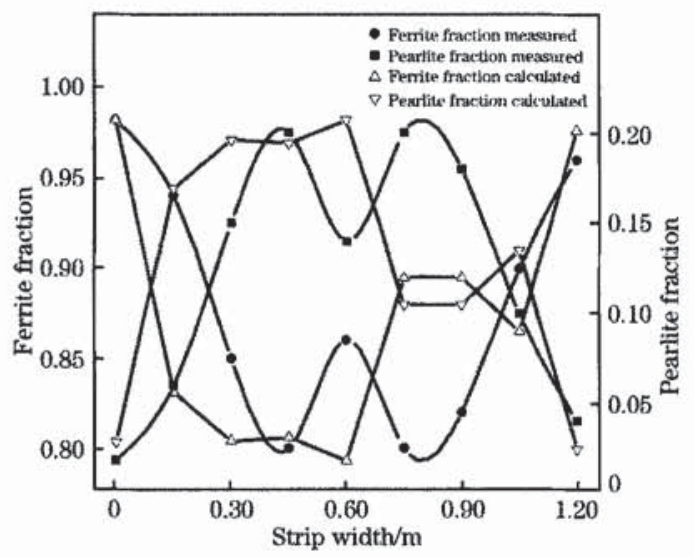

Fig. 8 Microstructure measurement along transverse direction of strip

\section{3 Stress analysis results}

Because the transverse and normal stresses in steel strip are very small and the strip flatness is mainly attributed by longitudinal stress distribution along transverse direction, only longitudinal stresses are considered in this work. Fig. 9 is longitudinal stress distributions along transverse direction at different cooling stages without initial stress and phase transformation. The thermal stress in strip increases as the temperature of strip decreases rapidly after strip enters into water cooling zone. The reasons for

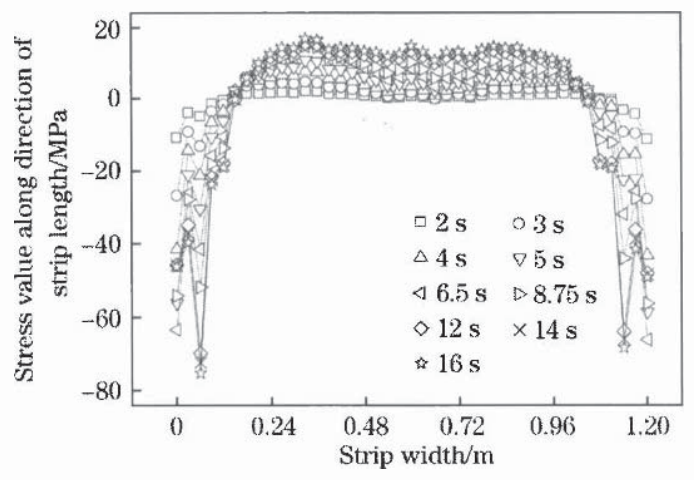

Fig. 9 Longitudinal stress distribution along transverse direction 
thermal stress generation are uneven temperature distribution and high cooling rate. Compressive stress at strip edge region reaches almost $80 \mathrm{MPa}$, and mainly concentrates within the range of $120 \mathrm{~mm}$ to the strip edge. Temperature decrease within strip edge leads to the residual stress distribution pattern of tensile stress at strip center region and compressive stress at strip edge region.

In this part, phase transformation and initial stress were considered to analyze the internal stress evolution in strip. Two working conditions of no initial stress and initial stress distribution of 10 IU flatness were taken into account. The calculated results of stress can be seen as shown in Fig. 10. From the comparison, it is known that phase transformation behavior has a great influence on the internal stress. The largest compressive stress at the strip edge can reach about $180 \mathrm{MPa}$ when the effects of microstructural phase transformation on internal stress are included in material constitutive function. This illustrates that stress generated due to phase transformation is large and it is even bigger than thermal stress. The range of strip edge subjected to compressive stress also enlarges to nearly $200 \mathrm{~mm}$. However it is about $120 \mathrm{~mm}$ when thermal stress is considered only. That is to say that the edge wave defect will be larger when microstructural evolution is taken into account than that of only considering thermal stress. In the center part of strip, stress also has an increase of about $20 \mathrm{MPa}$. Internal stress calculation result in which phase transformation behavior has been considered is very close to those obtained by $\mathrm{H}$ Yoshida ${ }^{[3]}$ and $\mathrm{CAI}$ Zheng ${ }^{[5]}$. Not only the stress distribution pattern but also the magnitude and distribution area have good agreement.

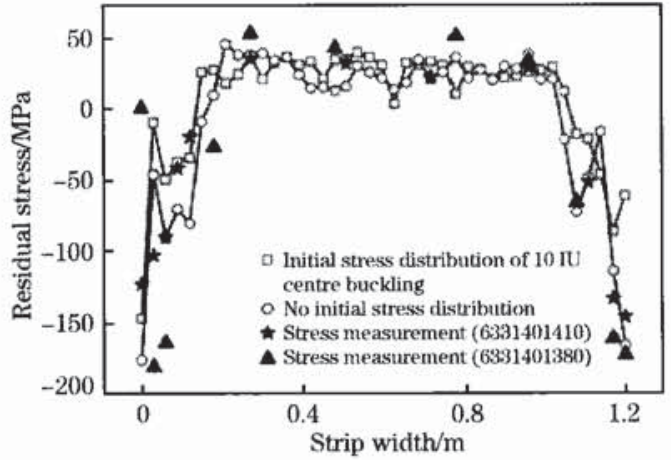

Fig. 10 Calculated and measured results of longitudinal stress distribution along strip's transverse direction

Besides comparison with the results of references, for verifying this analysis model directly, residual stress measurements on the steel strip were also carried out. X-ray diffraction was adopted as stress measuring method, and the detailed measurements of residual stress also can be seen in Fig. 10. Two HP295 strip samples with length in $4.5 \mathrm{~m}$, width in $1200 \mathrm{~mm}$, and thickness in $4.0 \mathrm{~mm}$ were cut at the position of nearly $15 \mathrm{~m}$ to strip coil heads. Strip flatness values of samples were recorded by the flatness gauge at the exit of the finish rolling mill, and the detailed information is: there were $10 \mathrm{IU}$ and $-10 \mathrm{IU}$ flatness values within the heads of $50 \mathrm{~m}$ in the strip coil 6331401410 and 6331401380 , respectively. There is a great agreement between the measurements and the calculations not only on the stress distribution pattern but also on the magnitude level.

In accordance with the analysis results mentioned above, it can be deduced that strip shape will develop to the trend of edge wave, and this phenomenon has been observed during the actual production as shown in Fig. 11.

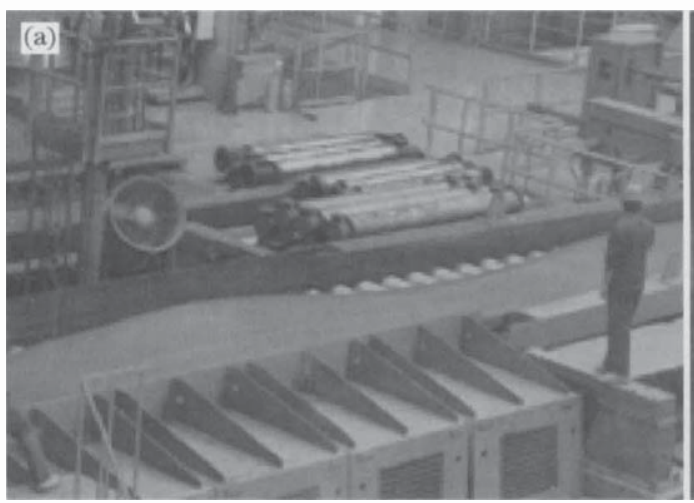

(a) After cooling and before downcoiler;

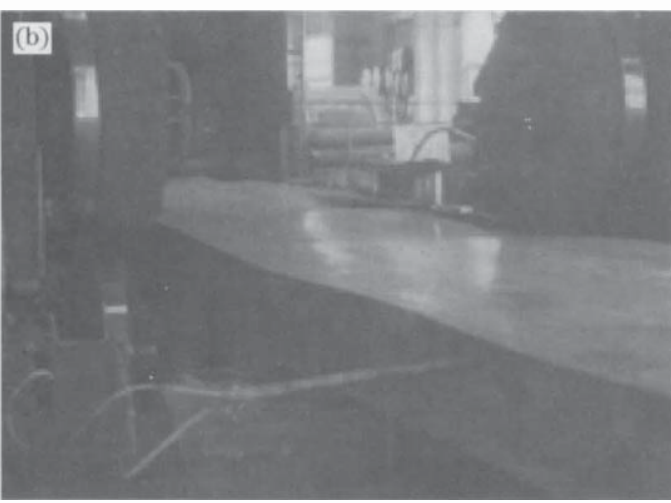

(b) Uncoiling process.

Fig. 11 Onsite observation of edge buckles on strip 


\section{Conclusions}

One thermal, microstructural and mechanical coupling analysis model for predicting flatness change of steel strip during the run-out table cooling was established using ABAQUS finite element software in this work.

1) K Esaka phase transformation kinetics model was employed to calculate the phase transformation happened during the cooling process of hot rolled strip, and coupled with temperature calculation using the user subroutine program HETVAL.

2) Elasto-plasticity constitutive equations of steel material including thermal and microstructural coupling behaviors were deduced. Conventional elastic and plastic strains, thermal strain, phase transformation strain resulted by phase volume change and transformation induced plastic strain were taken into account and realized in the total strain calculation of the user subroutine program UMAT.

3 ) The conclusion that the flatness of steel strip will develop to edge wave under the functions of the transverse thermal and microstructural behavior differences during the run-out table cooling procedure was acquired through the analysis results of this model. Calculation results of this analysis model agree well with the actual measurements.

\section{References:}

[1] LIU Zheng-dong. Experiments and Mathematical Modeling of Controlled Runout Table Cooling in a Hot Rolling Mill [D]. Vancouyer: The University of British Columbia, 2001 (in Chinese).

[2] Serajzadeh S. Prediction of Temperature Distribution and Phase Transformation on the Run-(Out Table in the Process of Hot Strip Rolling [J]. Applied Mathematical Modelling, 2003, 27 (2): 861

[3] Yoshida H. Analysis of Flatness of Hot Rolled Steel Strip After Cooling [J]. Transactions ISIJ, 1984, 24(3): 212.

[4] Wang Shyi-chin, Chiu Fon-jen, Ho Tsan-ying. Characteristics and Prevention of Thermomechanical Controlled Process Plate Deflection Resulting From Uneven Cooling [J]. Materials Science and Technology, 1996, 12(1): 64 .

[5] CAI Zheng. Research on Buckling Behavior of Hot-Rolled Strip After Cooling [D]. Shenyang: Northeastern University, 1998 (in Chinese).

[6] Han H N, Lee J K, Kim H J, et al. A Model for Deformation, Temperature and Phase Transformation Behavior of Steels on Run-Out Table in Hot Strip Mill [J]. Journal of Materials Processing Technology, 2002, 128: 216.

[7] Colás R, Leduc L A, Neri M A. Prediction of Shape Defects During Cooling of Hot Rolled Low Carbon Steel Strip [J]. Ir- onmaking and Steelmaking, 2004, 31(1): 93.

[8] Zhou Zhong-qing, Thomson P F, Lam Y, et al. Numerical Analysis of Residual Stress in Hot-Rolled Steel Strip on the RunOut Table [J]. Journal of Materials Processing Technology, 2003,$132 ; 184$.

[9] Ogai H, Ito M, Hirayama R. Consistent Shape Prediction Simulator After Hot Rolling Mill [J]. Nippon Steel Technical Report, 2004, 89: 43.

[10] ZHOU Zhong-qiing, Lam Y, Thomson P F, et al. Numerical Analysis of the Flatness of Thin, Rolled Steel Strip on the Runout Table [J]. Proceedings of the Institution of Mechanical Engineers, Part B: Journal of Engineering Manufacture, 2007, 221(2): 241.

[11] Nikitenko E, Gris B C. A Mechanism of Post-Rolling Deterioration in Hot Band Flatness During Coiling [J]. Iron and Steel Technology, 2009, 6(10): 60 .

[12] Pacheco P M C L, Savi M A, Camarào A F. Analysis of Residual Stresses Generated by Progressive Induction Hardening of Steel Cylinders [J]. Journal of Strain Analysis, 2001, 36 (5): 507.

[13] Yao Xin, Zhu L H, Li M Victor. Finite Element Analysis of Residual Stress and Distortion in an Eccentric Ring Induced by Quenching $[\mathrm{J}]$. Transactions of Materials and Heat Treatment Proceedings of the 14th IFHTSE Congress, 2004, 25 (5): 746 .

[14] Silva E P, Pacheco P M C L, Savi M A. Finite Element Analysis of the Phase Transformation Effect in Residual Stresses Generated by Quenching in Notched Steel Cylinders [J]. Journal of Strain Analysis, 2005, 40(2): 151.

[15] Casotto S, Pascon F, Habraken A M, et al. Thermo-Mechanical-Metallurgical Model to Predict Geometrical Distortions of Rings During Cooling Phase After Ring Rolling Operations [J]. International Journal of Machine Tools and Manufacture, 2005, 45: 657 .

[16] Kwon O. A Technology for Prediction and Control of Microstructural Changes and Mechanical Properties in Steel $[\mathrm{J}]$. ISIJ International, 1992, 32(3): 350.

[17] Taleb L, Sidoro F. A Micromechanical Modeling of the Greenwood-Johnson Mechanism in Transformation Induced Plasticity [J]. International Journal of Plasticity, 2003, 19: 1821.

[18] ABAQUS Standard Version 6. 5. User Manual, Theory Manual $[\mathrm{M}]$. Michigan: Hibbitt, Karlsson and Sorensen, Inc, 2005.

[19] Becker M, Jordan C, Lachhander S K, et al. Prediction and Measurement of Phase Transformations, Phase-Dependent Properties and Residual Stresses in Steels [C]// Proceedings of the 7th International Conference on Trends in Welding Research. Callaway Gardens Resort, Pine Mountain, Georgia, USA, 2005: 1007.

[20] Wang Xiao-dong, Yang Quan, He An-rui. Calculation of Thermal Stress Affecting Strip Flatness Change During RunOut Table Cooling in Hot Steel Strip Rolling [J]. Journal of Materials Processing Technology, 2008, 207: 130.

[21] ZHANG Mai-cang, DONG Jian-xin, ZENG Yan-ping, et al. Dynamical Microstructure Evolution of Q235 Low Carbon Steel During High Temperature Deformation [J]. Journal of University of Science and Technology Beijing, 2005, 27(2): 183 (in Chinese). 